\title{
The role of interleukin-21 in HIV infection
}

\author{
Suresh Pallikkuth ${ }^{1}$, Anita Parmigiani ${ }^{1}$, and Savita Pahwa ${ }^{1}$ \\ ${ }^{1}$ Department of Microbiology \& Immunology, University of Miami Miller School of Medicine, Miami, \\ FL-33136
}

\section{Abstract}

Interleukin (IL)-21 is one of a group of cytokines including IL-2, IL-4, IL-7, IL-9 and IL-15 whose receptor complexes share the common $\gamma$ chain $\left(\gamma_{c}\right)$. Secretion of IL-21 is restricted mainly to $\mathrm{T}$ follicular helper (TFH) CD4 $\mathrm{T}$ cell subset with contributions from Th17, Natural Killer (NK) T cells, but the effects of IL-21 are pleiotropic, owing to the broad cellular distribution of the IL-21 receptor. The role of IL-21 in sustaining and regulating T cell, B cell and NK cell responses during chronic viral infections has recently come into focus. This chapter reviews current knowledge about the biology of IL-21 in the context of HIV infection.

\section{Keywords}

IL-21 and T cells; IL-21 and B cells; HIV and IL-21; immunomodulation by IL-21; IL-21 and immunity

\section{Introduction}

Cytokines are immune mediators that are important in initiating, maintaining and regulating immune responses and inflammation. The cytokine interleukin (IL)-21 belongs to the family of cytokines that includes IL-2, IL-4, IL-7, IL-9 and IL-15, all of whom utilize the common $\gamma$ chain $\left(\gamma_{c}\right)$ CD132 in their receptor complexes for delivering intracellular signals in their target cells. The unfolding spectrum of the effects of these cytokines has stimulated interest in the search for ways to harness them in strategies to prevent HIV infection as vaccine adjuvants and as therapeutic tools in facets of the acute and chronic phases of the disease in infected hosts. New insights into the biology of IL-21 and its influence on the immune system in different clinical settings indicate that it is a unique cytokine that targets a wide range of immune cells, thus offering an interesting perspective of its potential clinical utility.

A broad range of cells express the receptor for IL-21 (IL-21R) resulting in pleiotropic activity of IL-21, and the cytokine has been investigated as a therapeutic modality in a number of malignant disorders and viral infections [reviewed in (1-5)]. Following successes in animal tumor models, IL-21 entered human clinical trials in patients with metastatic renal

(C) 2012 Elsevier Ltd. All rights reserved.

Corresponding author: Savita Pahwa, MD, Professor, Microbiology and Immunology, University of Miami Miller School of Medicine, 1580 NW 10th Avenue, BCRI 712, Miami, FL 33136, Phone: 305-243-7732; Fax: 305-243-7211;

spahwa@med.miami.edu.

Publisher's Disclaimer: This is a PDF file of an unedited manuscript that has been accepted for publication. As a service to our customers we are providing this early version of the manuscript. The manuscript will undergo copyediting, typesetting, and review of the resulting proof before it is published in its final citable form. Please note that during the production process errors may be discovered which could affect the content, and all legal disclaimers that apply to the journal pertain.

The authors have no financial conflicts of interest. 
cell carcinoma, metastatic melanoma and relapsed/refractory indolent non-Hodgkin's lymphoma, with demonstrable antitumor activity [reviewed by Hashmi and Van Veldhuizen (6)]. In phase I studies in patients with metastatic melanoma, IL-21 was well tolerated and resulted in increases in mRNA for IFN- $\gamma$, perforin, and granzyme B in CD8 T cells and natural killer (NK) cells (7-10). Emerging data implies that IL-21 could play a pivotal role in both acute $(11,12)$ and chronic $(13-15)$ viral infections in mice and also most recently in chronic hepatitis B and C virus infections (16-19) in humans, thus making this cytokine relevant for investigation in the context of HIV infection.

HIV infection is characterized by the progressive qualitative and quantitative deficiency of CD4 T cells (20) and broad immunological defects that include immunosuppression in concert with increased inflammation and immune activation (21). CD4 T cell depletion is evident in circulation as well as in lymphoid tissue. Since CD4 T cells are the main source of IL-21, there is considerable interest in determining whether and how HIV infection alters IL-21 production. Recent studies have ascribed an important role to this cytokine in preservation of virus control in HIV infected patients with different disease states (22-26). Findings from these studies and emerging results from in vivo IL-21 administration in rhesus macaques support the idea that IL-21 could prove to be beneficial in particular clinical settings, and underscore the need to investigate how this cytokine regulates the overall immunological outcome during HIV infection. In this review we summarize the biology of IL-21, its role on modulating adaptive immune responses, its alterations during the course of HIV infection and its potential therapeutic utility.

\section{Interleukin-21 and its receptor}

The IL21 gene is encoded on chromosome 4 in humans, and the mature human IL-21 polypeptide is 131 amino acids in length with 57\% amino acid homology to its murine counterpart $(27,28)$. IL-21 is produced by CD4 T cells, in particular T follicular helper (TFH) cells, T helper 17 (Th17) cells, and also by NKT cells (27, 29-31). There are indications that it can also be expressed by CD8 T cells under certain conditions $(14,28$, 29). As with other $\gamma_{c}$-sharing cytokines, the binding of IL-21 to its receptor leads to the activation of the Janus-kinase-family proteins (JAK) 1 and 3. Downstream of JAK recruitment, IL-21 mainly activates signal transducer and activator of transcription (STAT) 3 , and to a weaker and more transient degree, STAT1, STAT4 and STAT5 (32, 33). IL-21 also activates extracellular signal-regulated protein kinases (ERK) 1/2 that are mitogenactivated protein kinases (MAPK) in neoplastic cells, epithelial cells, and monocytes (34). These signal transduction pathways eventually modulate the transcription program within the activated cell, thus regulating its phenotype, function and fate. STAT3, B-cell lymphoma 6 (Bcl6), transcription factor 7 (Tcf7), and lymphoid enhancer binding factor 1 (Lef1) are the main transcription factors involved in the IL-21 signaling of CD4 and CD8 T lymphocytes, and are mainly expressed in cells that are less terminally differentiated and maintain their proliferative capacity $(35,36)$.

The human $I L 21 R$ gene is located adjacent to $I L 4 R A$ gene on chromosome 16 , and its amino acid sequence is most closely related to IL-2R $\beta$ and it encodes a 538 amino acid protein. Human IL-21R shares $62 \%$ amino acid sequence similarity with its murine counterpart, encoded on chromosome $7(27,33)$. The distinct IL-21R chain couples with the $\gamma_{c}$ and together form the cytokine receptor complex (27). It is possible that IL-21 could bind to IL-21R in the absence of the $\gamma_{c}$, but the intracellular signaling events proceed only when the $\gamma_{\mathrm{c}}$ is present (27). IL-21R is constitutively expressed on T, B, and NK cells and level of expression is highest on B cells $(33,37)$. T cells express low levels of IL-21R that increase upon T cell receptor (TCR) stimulation $(33,37)$. IL-21R is expressed in tissues, predominantly in cells of lymphoid tissues including spleen, thymus and lymph nodes (27, 
33,37 ), and less often in cells from lung and small intestine. IL-21R is also constitutively expressed on additional cell types including dendritic cells (DC), macrophages, fibroblasts, and epithelial cells (38-41). This broad range of expression of IL-21R explains the pleiotropic effect of IL-21 in the regulation of immune response.

\section{CD4 T cells and IL-21}

IL-21 influences lineage commitment and differentiation of several CD4 subsets in an autocrine as well as a paracrine manner. Upon engagement of their TCR, CD4 T helper cells differentiate into several possible fates and secrete cytokines and chemokines that orchestrate an immune response by promoting antibody production, CD8 T cell-mediated cytotoxicity and anti-pathogen activities. IL-21 plays an important role in differentiation of two major IL-21-producing CD4 T cell subsets, the TFH (42-45) and the Th17 cells (30). Differentiation of CD4 T lymphocytes into TFH cells is promoted by two key transcription factors, Bcl6 and c-Maf (46). In both mice and humans, c-Maf is up-regulated by inducible T-cell co-stimulator (ICOS) signal, and promotes IL-21 expression (46-48). IL-21 can also induce c-Maf, thus providing a positive self-regulatory loop that maintains IL-21 expression in TFH cells (49). IL-21 can induce Bcl6 $(31,50)$ which is important for the induction of migration genes that control homing to the lymph nodes, namely CXC-chemokine receptor (CXCR)4, CXCR5, CC-chemokine receptor (CCR)7, and genes that are involved in T-B interactions including CD40L, inducible co-stimulator (ICOS), CXC-chemokine ligand (CXCL)13 (46), and the critical proteins SLAM-associated protein (SAP) and programmed death (PD)-1. However, Bcl6 does not alter the expression of IL-21 in primary human CD4 T cells (46).

TFH-derived IL-21 orchestrates many aspects of B cell differentiation and function, such as proliferation, somatic hypermutation, germinal centre (GC) development and maintenance, extrafollicular B cell responses, and development of memory B cells and plasma cells (5155). Although the importance of TFH cells for B cell differentiation and function was initially described for TFH cells residing within germinal centers (GC), it was recently demonstrated that peripheral $\mathrm{CXCR}^{+}$memory $\mathrm{CD} 4 \mathrm{~T}$ cells share functional properties with the GC TFH cells, such as the ability to induce naïve and memory B cells to produce immunoglobulins via IL-21 secretion (56). Notably, these peripheral CXCR5+ CD4 T cells are absent in circulation of patients with ICOS deficiency (57) who also lack germinal centers, thereby attesting to their relevance of peripheral TFH in supporting B cell function.

IL-21 is also important for the differentiation of Th17 cells, a CD4 T cell subset that is involved in clearance of extracellular pathogens particularly in the gut, and in the pathogenesis of several autoimmune processes (58). IL-21 induces IL-23R expression, which is critical for Th17 lineage commitment, and IL-17 production (59-61). Moreover, studies in mouse models have shown that IL-21 promotes its own expression through STAT3 activation in an autocrine feedback loop in Th17 cells $(61,62)$. IL-21 mRNA and protein are very highly expressed in Th17 cells, at levels approximately fivefold higher than in Th1- and Th2-polarized cells $(62,63)$. Production of IL-21 by Th17 cells is positively regulated by IL-6 (61) which is another cytokine capable of activating STAT3. A CD4 T cell subset that is negatively influenced by IL-21 consists of the Forkhead box P3 (Foxp3)+ regulatory CD4 T cells (Treg). Indeed, IL-21 inhibits the transforming growth factor beta (TGF $\beta$ )-mediated differentiation of naive CD4 T cells into Tregs (63) and also inhibits T cell production of IL-2, which is a fundamental cytokine for Treg growth and survival, thereby impairing Treg homeostasis and allowing conventional CD4 Th cells to become resistant to the inhibitory activity of Tregs (64-66). Thus overall IL-21 appears to promote Th17 and TFH cell subsets while inhibiting Treg cell homeostasis and function. 


\subsection{IL-21 and CD4 T cells in HIV infection}

Despite their relevance in B cell function and IL-21 production, little is known about TFH cells in HIV infection. A recent study has demonstrated that spatial and phenotypical alterations occur in the GC TFH of SIV-infected rhesus macaques (RM). These anomalies in the TFH compartment appear to be associated with increased B cell turnover and the potential establishment of a viral reservoir within the GC during SIV infection (67). The role of TFH in HIV infection in the context of B cell function and HIV antibody responses as well as Ab responses to vaccines is increasingly being investigated. HIV-specific IL-21producing CD4 T cells detected in blood during untreated acute and chronic HIV infection have been reported to express CXCR5 and to have an effector memory phenotype (26). A study by our group indicates an important role for peripheral TFH cells in influenza vaccineinduced antibody responses of HIV infected patients (Pahwa S, manuscript submitted).

Recent studies have addressed the effects of HIV infection upon IL-21 production by CD4 T cells and upon plasma IL-21 levels (23-26). In cross-sectional and longitudinal studies in different groups of HIV infected patients, Iannello et al. reported on the dynamics of IL-21 production during HIV infections and its consequence on CD4 T cell survival and frequencies of HIV-specific CD8 T cells $(23,24)$. Plasma levels of IL-21 were lower in HIV-infected individuals by comparison with non-infected control subjects. The levels of IL-21 correlated with CD4 T cell counts, suggesting that CD4 T cells were the predominant source of IL-21 (24). Consequently, immune reconstitution with increase in CD4 T cell counts following ART initiation was associated with a concordant increase in IL-21 levels (23). In this latter study, plasma IL-21 levels were inversely correlated with plasma HIV load and circulating levels of IL-21 were higher in elite controllers who are HIV-infected patients able to contain viral replication without any treatment, as compared to progressors, pointing to a role of IL-21 in virologic control. Compared to uninfected CD4 T cells, IL-21 production was reduced in CD4 T cells infected in vitro with HIV (23). This was in part attributable to HIV induced negative modulation of c-Maf, the transcription factor required for IL-21 expression. These observations suggest that IL-21 is progressively lost during HIV infection, and that its production is associated with control of virus replication in vivo. Another study however reported that HIV infected individuals have greater circulating IL-21 producing CD4 $\mathrm{T}$ cells in blood compared to uninfected individuals (26). In agreement with others, the authors also found that elevated frequencies of HIV-specific IL-21 producing CD4 T cells correlated with relative viral control, probably by promoting CD8 T cell maintenance and function (26).

Th17 cells are believed to be critical for gut mucosal integrity during HIV infection $(68,69)$. In chronic HIV and SIV infections, it is now well established that preferential loss of Th17 cells at mucosal sites and generalized immune activation are interrelated and contribute to the pathogenesis of these infections (70-74). Imbalances in the ratio of Th17:Tregs and Th17:Th1 cells have also been reported, with a decline in the Th17 population correlating with more pronounced immune activation and disease progression $(71,73,75)$. Long term non progressors (LTNP), who are HIV-infected individuals with low level of virus replication in the absence of therapy and do not experience CD4 $\mathrm{T}$ cell depletion, have intact CD4 T cell populations, including Th17, in the gut mucosa and a preserved $\mathrm{T}$ cell population expressing gut homing molecules in the peripheral blood (73). This is associated with reduced markers of microbial translocation, suggesting that, similarly to nonpathogenic SIV infection, LTNP preserve the balance of CD4 T cell populations in blood and gut mucosa, which may contribute to the lack of disease progression and overall enhanced immune response (73). Since Th17 cells are a major source of IL-21, preferential depletion of this subset post-infection could greatly impact IL-21 levels, thus affecting the overall outcome of humoral and cellular immunity. The contribution of IL-21 in controlling the equilibrium of different CD4 T cell subsets during HIV and SIV infections might be of significance in the 
regulation of immune responses during HIV infection. Given the roles of IL-21 in both promoting Th17 development and in suppressing Treg levels (59-61, 63-66), it is possible that alterations in the availability of IL-21 in the intestinal mucosa and other tissue sites, in addition to the systemic levels, could be of relevance in HIV disease pathogenesis. Further investigations are warranted to define the true relationship of IL-21 upon immune regulation in the context of HIV infection.

\section{CD8 T cells and IL-21}

The main function of CD8 T cells, also called cytotoxic T lymphocytes (CTL), is to kill virally infected and transformed tumor cells through the release of perforin, a membranedisrupting protein, and granzymes, a family of serine proteases $(76,77)$. Optimal CD8 T cell differentiation and acquisition of effector cytotoxic function is modulated by the strength and duration of the TCR signal $(78,79)$, costimulation $(80)$, and the presence of proinflammatory mediators such IL-12 and type I interferons $(81,82)$. Moreover, the cytokine milieu at the time of antigen presentation may further influence the outcome of CD8 T cell activation. In particular, IL-21 can induce acquisition of cytotoxic molecules and differentiation into memory cells, ultimately promoting CD8 T cell antiviral and antitumor activities.

Studies in mice have shown that IL-21, in combination with IL-15 and IL-7, promotes CD8 $\mathrm{T}$ cell expansion and cytotoxic function in vitro (83). Similarly, human CD8 T cells activated in vitro in the presence of this cytokine accumulate cytotoxic molecules perforin, granzyme B (84) and granulysin (85), and increase their in vitro cytotoxic activity (84). The acquisition of this highly cytotoxic function is associated with a memory phenotype, characterized by the expression of the memory-associated markers CCR7, CD27, CD28 in human $(84,86-88)$, CD44 and CD62L in mice $(35,89)$. The establishment of a stable memory pool is presumably mediated by the activation of STAT3 $(90,91)$, which is the main transcription factor activated by IL-21. The murine model has provided compelling evidence for a critical role of IL-21 in controlling both acute $(11,92)$ and chronic (13-15) viral infections. This cytokine is necessary for the generation of virus-specific memory CD8 T cells after the resolution of an acute infection (92), for acquisition of polyfunctional CD8 T cells during both acute (11) and chronic (14) viral infections, and to contain exhaustion of CD8 T cells (15) while promoting their effector function (13) during chronic Lymphocytic Choriomeningitis Virus (LCMV) infection. Taken together, these findings are relevant for their translational merit, since they provide a rationale for investigating IL-21 in HIV infections of humans for its influence on cell-mediated immune responses.

\subsection{IL-21 and CD8 T cells in HIV}

While correlates of immune protection in HIV infection are not well understood, cytotoxic $\mathrm{T}$ cells (93-95) and more recently NK cells have been shown to play important roles in control of HIV replication $(96,97)$. Elevated expression of perforin in HIV-specific CD8 T cells and increased ability to kill HIV-infected CD4 T cells are features associated with LTNP status $(95,98,99)$. Initial suggestion that IL-21 could enhance cytotoxic potential of CTL in HIV infection first came from experiments that we performed with peripheral blood lymphocytes of HIV infected patients and healthy donors. We observed that IL-21 could enhance the expression of the cytotoxic molecules perforin and granzyme B in CD8 T cells of HIV infected individuals in vitro (100). The IL-21-induced selective increase in perforin expression did not drive the proliferation or the spontaneous degranulation of the CD8 T cell population, as were promoted by IL-15 (100). Results from this study indicated that CD8 T cells of patients with HIV could be modulated by IL-21 to enhance cytotoxic molecules without undergoing overt cellular activation, and led to the concept that IL-21 as an immunotherapeutic agent was potentially capable of improving overall viral containment 
without promoting virus replication. The initial observations have been confirmed and expanded by several other studies, showing the importance of IL-21 in inducing the maintenance, survival and cytotoxicity during HIV infection $(22,25,26,101)$. Granulysin, a molecule with anti-microbial activity expressed by CD8 T cells and NK cells in humans [reviewed in (102)], can be induced in CD8 T cells from HIV-individuals via IL-21 and IL-15-mediated STAT3 and STAT5 activation (85). Infection of peripheral blood mononuclear cells (PBMC) with HIV significantly reduces IL-21-induced granulysin production by CD8 T cells (85). Collectively, these studies reveal important roles for IL-21 in shaping the functional properties of CD8 $\mathrm{T}$ cell responses that may be impaired during HIV-1 infection.

There is strong rationale for the ability of IL-21 to influence the phenotypic and anti-viral functional properties of CD8 T cells in HIV infection. Notably, functional HIV-specific CD8 T cell responses, as detected by the ability to produce IL-2 and IFN $\gamma$, tend to be greater in HIV infected individuals with higher serum levels of IL-21 (101). HIV-specific CD8 T cells from chronically infected individuals have also been shown to express higher levels of the IL-21R than their cytomegalovirus (CMV)-specific counterparts, indicating sensitivity to IL-21, and culturing these cells in the presence of IL-21 promotes their survival and expansion $(26,101)$. IL-21 also impacts other functional attributes of CD8 T cells that affect their ability to contain infections. Chevalier et al reported that IL-21 production by CD4 T cells of HIV controllers enhances perforin levels in HIV-1-specific CD8 T cells from chronic progressors even in late stages of HIV disease (22). Moreover, ex vivo treatment with IL-21 enhances the ability of HIV-specific CD8 T cells to inhibit viral replication in vitro, indicating the immunomodulatory property of IL-21 on CD8 T cell antiviral activity (22). In a study involving elite controllers, Williams et al. analyzed the ability of CD4 and CD8 T cells to produce several cytokines in addition to IL-21 following ex vivo stimulation with overlapping HIV-1 peptides (25). This study found that both CD4 and CD8 T cells are able to produce IL-21 in response to HIV-1 infection, with the latter cell type being more closely associated with viral control (25). Overall, these data suggest that HIV-1-specific IL-21 CD4 T cell responses might contribute to the control of viral replication by enhancing CD8 T cell activity in humans, and thus may be of importance for vaccine design.

\section{4. $B$ cells and IL-21}

B cells contribute to immunity to infections by serving as antigen-presenting cells and, most significantly, by giving rise to pathogen-specific antibodies, and most of the functional aspects of B cells are regulated by IL-21. In B cells, this cytokine can induce proliferation, differentiation, class switching or death, depending upon the type of antigenic stimulation and accessory signals $(37,103)$, making the IL-21-elicited signaling the most important among all the $\gamma_{\mathrm{c}}$ cytokines for long-lived humoral immunity (104). Naïve human B cells are efficiently induced to secrete immunoglobulin via IL-21 following cognate T-B interaction $(53,56)$. Recently, expression of the IL-21R on B cells was shown to be critical for development of memory B cells (105). IL-21-elicited STAT3 activation induces B cell maturation with expression of plasma cell (PC) associated genes, phenotypic PC formation and antibody secretion $(53,106-110)$. In germinal centers, IL-21 is important in developing and maintaining the $\mathrm{GC}$ reaction by regulating $\mathrm{Bcl} 6$ expression $(50,111,112)$.

\subsection{IL-21 and B cells in HIV}

Extensive characterization of B cells in patients with established HIV infection points to a state of excessive $\mathrm{B}$ cell activation with impaired survival resulting in abnormal distribution of B cell maturation subsets (reviewed in 113). The lower survival of memory B cells is attributed to disrupted cytokine signaling resulting in increased transcriptional activity of 
Foxo3a with increased expression of its proapoptotic target TRAIL (114). Accumulation of immature transitional B cells, activated mature cells, tissue-like exhausted and short lived plasmablasts occurs in association with reduced naïve and resting memory B cells. Following institution of antiretroviral therapy (ART), the distribution of B cell subsets does not completely revert to normal, and the $\mathrm{CD} 27^{+}$resting memory B cells remain significantly decreased in comparison to healthy uninfected donors, despite virologic control and CD4 T cell recovery $(115,116)$ and display the Foxo3a/TRAIL signaling characteristics described above (114). Improvement in the survival and function of immune cells including B cells by immunotherapeutic approaches are desirable objectives in control of HIV. In a study of rMamu-IL-21 administration to chronically SIV-infected RM, we found a small but definite increase in the frequencies of $\mathrm{CD} 27^{+}$memory B cells with upregulation of IL-21R on both $\mathrm{CD} 27^{+}$memory and CD27 negative naïve B cells, together with an increase in anti-SIV antibodies in the serum of the IL-21-treated animals (117), providing further proof of a biologic activity of IL-21 on B cell populations.

Direct evidence for the role of IL-21 in supporting B cells of HIV infected individuals comes from a study of influenza vaccine-induced antibody response in a cohort of HIV+ subjects (118). This study demonstrated that the induction of IL-21 and IL-21R on B cells was associated with influenza Ab response in HIV-infected and healthy controls following H1N1/09 vaccination and that the upregulation of IL-21/IL-21R in the vaccine responder subjects corresponded with in vivo development of plasmablasts, that spontaneously secreted Ab, and memory B cells, that could be induced to secrete Ab following ex vivo stimulation with H1N1 antigen (118). Patients who did not respond to the H1N1/09 vaccine failed to develop these vaccine-induced characteristic B cells changes. These observations are consistent with a recent report in which IL-21-mediated signaling was found to be critical for long-lived humoral immunity and to restore antibody responses in IL2R $\gamma \mathrm{C} /$ JAK3-deficient patients with severe combined immunodeficiency after hematopoietic cell transplantation (104). In addition to the IL-21/IL-21R pathway, innate immune factors which influence the B cell development and differentiation were also defective in the H1N1/09 vaccine non-responder patient group (119). Based on these data and prior evidence for the role of IL-21 in promoting T-dependent B cell proliferation, isotype switching, differentiation of B cells into plasma cells and development of memory B cells $(53,106$, 120-122), IL-21 merits continued attention in the future for non-HIV and HIV vaccine responses. The fact that IL-21 production is mainly stimulated by activation of TFH as discussed above, it is important to determine if the B cell defects in HIV infected people are secondary to a deficiency in the CD4 TFH cell compartment and can be reversed by IL-21. The failure of recovery of memory B cells following ART however suggest long lasting intrinsic B cell defects in HIV infected people due to direct or indirect consequences of HIV infection.

\section{NK cells and IL-21}

Innate immunity is an important aspect of initial defense against infectious agents, including $\mathrm{HIV}$, and the capacity to mount very early strong innate immune response might favorably impact the subsequent course of infection including viral control. NK cells are prominent components of the innate arm of the immune response. NK cells, that have been shown to play important roles in HIV infection $(96,97)$, express IL-21R, and can be influenced by in vitro exposure to IL-21 (123). IL-21R is equally expressed on all NK cell subsets, as defined by the expression of CD16 and CD56, and IL-21 activates STAT3, MAPK and Akt to enhance NK cell functions $(101,123)$. IL-21 can also increase the expression of antiapoptotic proteins $\mathrm{Bcl}-2$ and $\mathrm{Bcl}-\mathrm{X}_{\mathrm{L}}$, enhancing NK viability without affecting their proliferation (101). 


\subsection{IL-21 and NK cells in HIV}

The CD56dim subset of NK cells, which is preferentially dependent upon IL-21, is reduced during HIV infection (123). Ex vivo treatment with IL-21 enhances the responses of NK cells from HIV-infected subjects by stimulating perforin production in a STAT3-dependent manner. IL-21 can also enhance HIV-specific antibody-dependent cell-mediated cytotoxicity (ADCC), secretory, and cytotoxic functions, as well as viability of NK cells from HIVinfected persons and the IL-21-activated NK cells inhibit viral replication when co-cultured with HIV-infected autologous CD4 T cells in a perforin-dependent manner (101). In a pilot study of rMamuIL-21 administration to SIV-infected macaques, we noted an increase in perforin-expressing NK cells (117). Together, these studies highlight the importance of IL-21 in augmenting NK effector functions in chronically HIV-infected individuals and SIV-infected animals, and point to its potential for immunotherapy or as a vaccine adjuvant.

\section{IL-21 as an immunotherapeutic agent in SIV/HIV infection}

Several studies in recent years have investigated immunotherapeutic properties of cytokines for their role as adjunctive therapy for HIV infection. Common $\gamma_{c}$-sharing cytokines IL-7 (124-126), IL-2 (127, 128), and IL-15 (128-130) have been tested in chronically SIVinfected animals. Administration of rIL-7 to uninfected or SIV-infected macaques demonstrated alterations in T cell homeostasis (124-126) with no effect on SIV replication (126). Administration of rIL-15 to healthy macaques was found to increase the frequency of long-lived effector memory CD4 and CD8 T cells (128). In SIV-infected RM, administration of rIL-15 was reported to augment effector memory CD8 T cells without reduction in viral replication in chronic infection $(129,130)$, whereas in acute SIV infection, rIL-15 administration resulted in increased peak viremia, which was attributed to increased CD4 T cell activation and proliferation (131). In addition, IL-12 also has been tested for its potential immunomodulatory benefits during chronic SIV infection $(132,133)$.

To evaluate safety, biological activity and immunomodulatory effects of IL-21, we conducted a pilot study of recombinant mamuIL-21 (rMamuIL-21) administration to chronically SIV-infected rhesus macaques (117). We observed that the cytokine was well tolerated up to the highest dose tested of $100 \mu \mathrm{g} / \mathrm{kg}$ body weight, and rapidly enhanced the expression of cytotoxic molecules perforin and granzyme B in T cells and NK cells within 48 hours of each dose. After each dose of IL-21, increases were noted in frequency and mean fluorescence intensity of granzyme B and perforin expression in memory and effector subsets of CD8 T cells in peripheral blood, in peripheral and mesenteric lymph node cells, and in peripheral blood memory and effector CD4 T cells. Consistent with our in vitro analysis in HIV infected individuals (100), no changes were observed in markers of T cell activation, $\mathrm{T}$ cell proliferation or plasma virus load and demonstrated favorable effects on $\mathrm{T}$, $\mathrm{B}$ and NK cells. Thus, this first in vivo IL-21 study in chronically SIV-infected animals provided evidence that IL-21 could augment the cytotoxic potential of T cells without enhancing discernible cellular activation, which is not the case with IL-7 or IL-15 (124, 131). The effects of different cytokines that have been investigated in the chronic SIV infection RM model are summarized in Table 1.

In a more recent study, IL-21 was administered during acute SIV infection (Pallikkuth S, manuscript submitted). IL-21 was found to increases cytotoxic molecules perforin and granzyme B on total and SIV gagspecific CD8 T cells and also homeostasis of total CD4 T and Th17 cells. In comparison to the control arm, IL-21 treated animals had reduced levels of $\mathrm{T}$ cell activation and microbial translocation without undesirable effects on viral load or $\mathrm{T}$ cell exhaustion. Further studies are needed to see if IL-21 given prior to infection can modulate the course of acute SIV infection and if it can be used as a suitable adjuvant to bolster cellular and humoral immunity. 


\section{Conclusions}

IL-21 plays important roles in regulating both innate and adaptive cellular immune responses. Data from studies of LCMV infection in mice point to the relevance of IL-21 in promoting and sustaining immunity in chronic LCMV infection. Data from studies in SIV infected rhesus macaques using rMamuIL-21 showed promising effects on cellular and humoral immunity without inducing immune activation. Since IL-21 plays an important role in the immune modulation of chronic virus infections in both mice (13-15) and humans (1619), its contribution to the control of latent infections and latent reservoirs of infectious agents needs to be defined. IL-21 administration in chronic SIV-infected RM provides hope that even at the late stages of infection, IL-21 has the potential to enhance the existing immunity (117). Recent studies have ascribed an important role to this cytokine in preservation of virus control in HIV infected patients with different disease states (22-26), and are outlined in Table 2.

The potential role of IL-21 as a therapeutic agent in the prevention or treatment of HIV infection however has not been conclusively established. Despite promising data in viral infections in mice and interesting findings in cells of HIV infected patients, definitive studies have not yet been performed. It is not known if IL-21 given prior to virus challenge in a rhesus macaque SIV model or if IL-21 given as a vaccine adjuvant can induce cellular or humoral immune responses that can prevent infection following virus challenge or delay time to infection. In chronic SIV infected animals, IL-21 did not induce cells to undergo proliferation or immune activation $(124,131)$, and demonstrated favorable effects on T, B and NK cells (summarized in Table 1). The lack of an effect of IL-21 on immune activation after in vivo administration in chronic SIV infection indicate that IL-21 has promise in immunotherapeutic approaches in SIV/HIV infection as it does not appear to affect factors that favor disease progression. These findings support continued exploration of the properties of IL-21 in experimental models of HIV/SIV infection in early and chronic stages in conjunction with ART and also in SIV/HIV vaccine or immunotherapeutic strategies. This information, along with knowledge gained from the studies on the effect of IL-21 in autoimmunity and immunity to tumors, may help in the development of IL-21-based adjuvants or therapies that could potentially be used in the fight against HIV.

\section{References}

1. Ma J, Ma D, Ji C. The role of IL-21 in hematological malignancies. Cytokine. 2011; 56:133-139. [PubMed: 21824785]

2. Sarra M, Franze E, Pallone F, Monteleone G. Targeting interleukin-21 in inflammatory diseases. Expert Opin Ther Targets. 2011; 15:695-702. [PubMed: 21391901]

3. Sondergaard H, Skak K. IL-21: roles in immunopathology and cancer therapy. Tissue Antigens. 2009; 74:467-479. [PubMed: 19845910]

4. Spolski R, Leonard WJ. Interleukin-21: basic biology and implications for cancer and autoimmunity. Annu Rev Immunol. 2008; 26:57-79. [PubMed: 17953510]

5. Yuan FL, Hu W, Lu WG, et al. Targeting interleukin-21 in rheumatoid arthritis. Mol Biol Rep. 2011; 38:1717-1721. [PubMed: 20848219]

6. Hashmi MH, Van Veldhuizen PJ. Interleukin-21: updated review of Phase I and II clinical trials in metastatic renal cell carcinoma, metastatic melanoma and relapsed/refractory indolent nonHodgkin's lymphoma. Expert Opin Biol Ther. 2010; 10:807-817. [PubMed: 20384523]

7. Davis ID, Brady B, Kefford RF, et al. Clinical and biological efficacy of recombinant human interleukin-21 in patients with stage IV malignant melanoma without prior treatment: a phase IIa trial. Clin Cancer Res. 2009; 15:2123-2129. [PubMed: 19276257] 
8. Davis ID, Skrumsager BK, Cebon J, et al. An open-label, two-arm, phase I trial of recombinant human interleukin-21 in patients with metastatic melanoma. Clin Cancer Res. 2007; 13:3630-3636. [PubMed: 17575227]

9. Frederiksen KS, Lundsgaard D, Freeman JA, et al. IL-21 induces in vivo immune activation of NK cells and CD8(+) T cells in patients with metastatic melanoma and renal cell carcinoma. Cancer Immunol Immunother. 2008; 57:1439-1449. [PubMed: 18286285]

10. Thompson JA, Curti BD, Redman BG, et al. Phase I study of recombinant interleukin-21 in patients with metastatic melanoma and renal cell carcinoma. J Clin Oncol. 2008; 26:2034-2039. [PubMed: 18347008]

11. Yi JS, Ingram JT, Zajac AJ. IL-21 deficiency influences CD8 T cell quality and recall responses following an acute viral infection. J Immunol. 2010; 185:4835-4845. [PubMed: 20844201]

12. Novy P, Huang X, Leonard WJ, Yang Y. Intrinsic IL-21 signaling is critical for CD8 T cell survival and memory formation in response to vaccinia viral infection. J Immunol. 186:27292738. [PubMed: 21257966]

13. Elsaesser H, Sauer K, Brooks DG. IL-21 is required to control chronic viral infection. Science. 2009; 324:1569-1572. [PubMed: 19423777]

14. Frohlich A, Kisielow J, Schmitz I, et al. IL-21R on T cells is critical for sustained functionality and control of chronic viral infection. Science. 2009; 324:1576-1580. [PubMed: 19478140]

15. Yi JS, Du M, Zajac AJ. A vital role for interleukin-21 in the control of a chronic viral infection. Science. 2009; 324:1572-1576. [PubMed: 19443735]

16. Pawlak K, Mysliwiec M, Pawlak D. Interleukin-21 in hemodialyzed patients: association with the etiology of chronic kidney disease and the seropositivity against hepatitis $\mathrm{C}$ virus infection. Clin Biochem. 2011; 44:1416-1420. [PubMed: 21945025]

17. Franks I. Viral hepatitis: Interleukin 21 has a key role in age-dependent response to HBV. Nat Rev Gastroenterol Hepatol. 2011; 8:243.

18. Ma SW, Huang X, Li YY, et al. High serum IL-21 levels after 12 weeks of antiviral therapy predict HBeAg seroconversion in chronic hepatitis B. J Hepatol. 2012; 56:775-781. [PubMed: 22173154]

19. Publicover J, Goodsell A, Nishimura S, et al. IL-21 is pivotal in determining age-dependent effectiveness of immune responses in a mouse model of human hepatitis B. J Clin Invest. 2011; 121:1154-1162. [PubMed: 21393863]

20. Sieg SF, Bazdar DA, Harding CV, Lederman MM. Differential expression of interleukin-2 and gamma interferon in human immunodeficiency virus disease. J Virol. 2001; 75:9983-9985. [PubMed: 11559831]

21. Giorgi JV, Hultin LE, McKeating JA, et al. Shorter survival in advanced human immunodeficiency virus type 1 infection is more closely associated with T lymphocyte activation than with plasma virus burden or virus chemokine coreceptor usage. J Infect Dis. 1999; 179:859-870. [PubMed: 10068581]

22. Chevalier MF, Julg B, Pyo A, et al. HIV-1-specific interleukin-21+ CD4+ T cell responses contribute to durable viral control through the modulation of HIV-specific CD8+ T cell function. $\mathrm{J}$ Virol. 2011; 85:733-741. [PubMed: 21047960]

23. Iannello A, Boulassel MR, Samarani S, et al. Dynamics and consequences of IL-21 production in HIV-infected individuals: a longitudinal and cross-sectional study. J Immunol. 2010; 184:114 126. [PubMed: 19949086]

24. Iannello A, Tremblay C, Routy JP, Boulassel MR, Toma E, Ahmad A. Decreased levels of circulating IL-21 in HIV-infected AIDS patients: correlation with CD4+ T-cell counts. Viral Immunol. 2008; 21:385-388. [PubMed: 18788946]

25. Williams LD, Bansal A, Sabbaj S, et al. Interleukin-21-Producing HIV-1-Specific CD8 T Cells Are Preferentially Seen in Elite Controllers. J Virol. 2011; 85:2316-2324. [PubMed: 21159862]

26. Yue FY, Lo C, Sakhdari A, et al. HIV-specific IL-21 producing CD4+ T cells are induced in acute and chronic progressive HIV infection and are associated with relative viral control. J Immunol. 2010; 185:498-506. [PubMed: 20519650]

27. Parrish-Novak J, Dillon SR, Nelson A, et al. Interleukin 21 and its receptor are involved in NK cell expansion and regulation of lymphocyte function. Nature. 2000; 408:57-63. [PubMed: 11081504] 
28. Parrish-Novak J, Foster DC, Holly RD, Clegg CH. Interleukin-21 and the IL-21 receptor: novel effectors of NK and T cell responses. J Leukoc Biol. 2002; 72:856-863. [PubMed: 12429707]

29. Coquet JM, Kyparissoudis K, Pellicci DG, et al. IL-21 is produced by NKT cells and modulates NKT cell activation and cytokine production. J Immunol. 2007; 178:2827-2834. [PubMed: 17312126]

30. Wei L, Laurence A, Elias KM, O'Shea JJ. IL-21 is produced by Th17 cells and drives IL-17 production in a STAT3-dependent manner. J Biol Chem. 2007; 282:34605-34610. [PubMed: 17884812]

31. Nurieva RI, Chung Y, Hwang D, et al. Generation of T follicular helper cells is mediated by interleukin-21 but independent of T helper 1, 2, or 17 cell lineages. Immunity. 2008; 29:138-149. [PubMed: 18599325]

32. Asao H, Okuyama C, Kumaki S, et al. Cutting edge: the common gamma-chain is an indispensable subunit of the IL-21 receptor complex. J Immunol. 2001; 167:1-5. [PubMed: 11418623]

33. Ozaki K, Kikly K, Michalovich D, Young PR, Leonard WJ. Cloning of a type I cytokine receptor most related to the IL-2 receptor beta chain. Proc Natl Acad Sci U S A. 2000; 97:11439-11444. [PubMed: 11016959]

34. Fuqua CF, Akomeah R, Price JO, Adunyah SE. Involvement of ERK-1/2 in IL-21-induced cytokine production in leukemia cells and human monocytes. Cytokine. 2008; 44:101-107. [PubMed: 18707899]

35. Hinrichs CS, Spolski R, Paulos CM, et al. IL-2 and IL-21 confer opposing differentiation programs to CD8+ T cells for adoptive immunotherapy. Blood. 2008; 111:5326-5333. [PubMed: 18276844]

36. Ozaki K, Spolski R, Ettinger R, et al. Regulation of B cell differentiation and plasma cell generation by IL-21, a novel inducer of Blimp-1 and Bcl-6. J Immunol. 2004; 173:5361-5371. [PubMed: 15494482]

37. Jin H, Carrio R, Yu A, Malek TR. Distinct activation signals determine whether IL-21 induces B cell costimulation, growth arrest, or Bim-dependent apoptosis. J Immunol. 2004; 173:657-665. [PubMed: 15210829]

38. Brandt K, Bulfone-Paus S, Jenckel A, Foster DC, Paus R, Ruckert R. Interleukin-21 inhibits dendritic cell-mediated $\mathrm{T}$ cell activation and induction of contact hypersensitivity in vivo. $\mathrm{J}$ Invest Dermatol. 2003; 121:1379-1382. [PubMed: 14675186]

39. Caruso R, Fina D, Peluso I, et al. IL-21 is highly produced in Helicobacter pylori-infected gastric mucosa and promotes gelatinases synthesis. J Immunol. 2007; 178:5957-5965. [PubMed: 17442980]

40. Monteleone G, Caruso R, Fina D, et al. Control of matrix metalloproteinase production in human intestinal fibroblasts by interleukin 21. Gut. 2006; 55:1774-1780. [PubMed: 16682426]

41. Ruckert R, Bulfone-Paus S, Brandt K. Interleukin-21 stimulates antigen uptake, protease activity, survival and induction of CD4+ T cell proliferation by murine macrophages. Clin Exp Immunol. 2008; 151:487-495. [PubMed: 18190607]

42. Chtanova T, Tangye SG, Newton R, et al. T follicular helper cells express a distinctive transcriptional profile, reflecting their role as non-Th1/Th2 effector cells that provide help for B cells. J Immunol. 2004; 173:68-78. [PubMed: 15210760]

43. Vinuesa CG, Tangye SG, Moser B, Mackay CR. Follicular B helper T cells in antibody responses and autoimmunity. Nat Rev Immunol. 2005; 5:853-865. [PubMed: 16261173]

44. Vinuesa CG, Cook MC, Angelucci C, et al. A RING-type ubiquitin ligase family member required to repress follicular helper T cells and autoimmunity. Nature. 2005; 435:452-458. [PubMed: 15917799]

45. Rasheed AU, Rahn HP, Sallusto F, Lipp M, Muller G. Follicular B helper T cell activity is confined to CXCR5(hi)ICOS(hi) CD4 T cells and is independent of CD57 expression. Eur J Immunol. 2006; 36:1892-1903. [PubMed: 16791882]

46. Kroenke MA, Eto D, Locci M, et al. Bcl6 and maf cooperate to instruct human follicular helper CD4 T cell differentiation. J Immunol. 2012; 188:3734-3744. [PubMed: 22427637]

47. Bauquet AT, Jin H, Paterson AM, et al. The costimulatory molecule ICOS regulates the expression of c-Maf and IL-21 in the development of follicular T helper cells and TH-17 cells. Nat Immunol. 2009; 10:167-175. [PubMed: 19098919] 
48. Hiramatsu Y, Suto A, Kashiwakuma D, et al. c-Maf activates the promoter and enhancer of the IL-21 gene, and TGF-beta inhibits c-Maf-induced IL-21 production in CD4+ T cells. J Leukoc Biol. 2010; 87:703-712. [PubMed: 20042469]

49. Pot C, Jin H, Awasthi A, et al. Cutting edge: IL-27 induces the transcription factor c-Maf, cytokine IL-21, and the costimulatory receptor ICOS that coordinately act together to promote differentiation of IL-10-producing Tr1 cells. J Immunol. 2009; 183:797-801. [PubMed: 19570826]

50. Nurieva RI, Chung Y, Martinez GJ, et al. Bcl6 mediates the development of T follicular helper cells. Science. 2009; 325:1001-1005. [PubMed: 19628815]

51. Crotty S. Follicular helper CD4 T cells (TFH). Annu Rev Immunol. 2011; 29:621-663. [PubMed: 21314428]

52. Fazilleau N, Mark L, McHeyzer-Williams LJ, McHeyzer-Williams MG. Follicular helper T cells: lineage and location. Immunity. 2009; 30:324-335. [PubMed: 19303387]

53. Ettinger R, Sims GP, Fairhurst AM, et al. IL-21 induces differentiation of human naive and memory B cells into antibody-secreting plasma cells. J Immunol. 2005; 175:7867-7879. [PubMed: 16339522]

54. Good KL, Bryant VL, Tangye SG. Kinetics of human B cell behavior and amplification of proliferative responses following stimulation with IL-21. J Immunol. 2006; 177:5236-5247. [PubMed: 17015709]

55. Pene J, Gauchat JF, Lecart S, et al. Cutting edge: IL-21 is a switch factor for the production of IgG1 and IgG3 by human B cells. J Immunol. 2004; 172:5154-5157. [PubMed: 15100251]

56. Morita R, Schmitt N, Bentebibel SE, et al. Human Blood CXCR5(+)CD4(+) T Cells Are Counterparts of T Follicular Cells and Contain Specific Subsets that Differentially Support Antibody Secretion. Immunity. 2011; 34:108-121. [PubMed: 21215658]

57. Bossaller L, Burger J, Draeger R, et al. ICOS deficiency is associated with a severe reduction of CXCR5+CD4 germinal center Th cells. J Immunol. 2006; 177:4927-4932. [PubMed: 16982935]

58. Dong C. TH17 cells in development: an updated view of their molecular identity and genetic programming. Nat Rev Immunol. 2008; 8:337-348. [PubMed: 18408735]

59. Korn T, Oukka M, Kuchroo V, Bettelli E. Th17 cells: effector T cells with inflammatory properties. Semin Immunol. 2007; 19:362-371. [PubMed: 18035554]

60. Hoeve MA, Savage ND, de Boer T, et al. Divergent effects of IL-12 and IL-23 on the production of IL-17 by human T cells. Eur J Immunol. 2006; 36:661-670. [PubMed: 16482511]

61. Zhou L, Ivanov II, Spolski R, et al. IL-6 programs T(H)-17 cell differentiation by promoting sequential engagement of the IL-21 and IL-23 pathways. Nat Immunol. 2007; 8:967-974. [PubMed: 17581537]

62. Nurieva R, Yang XO, Martinez G, et al. Essential autocrine regulation by IL-21 in the generation of inflammatory T cells. Nature. 2007; 448:480-483. [PubMed: 17581589]

63. Korn T, Bettelli E, Gao W, et al. IL-21 initiates an alternative pathway to induce proinflammatory T(H)17 cells. Nature. 2007; 448:484-487. [PubMed: 17581588]

64. Peluso I, Fantini MC, Fina D, et al. IL-21 counteracts the regulatory T cell-mediated suppression of human CD4+ T lymphocytes. J Immunol. 2007; 178:732-739. [PubMed: 17202333]

65. Li Y, Yee C. IL-21 mediated Foxp3 suppression leads to enhanced generation of antigen-specific CD8+ cytotoxic T lymphocytes. Blood. 2008; 111:229-235. [PubMed: 17921346]

66. Attridge K, Wang CJ, Wardzinski L, et al. IL-21 inhibits T cell IL-2 production and impairs Treg homeostasis. Blood. 2012

67. Hong JJ, Amancha PK, Rogers K, Ansari AA, Villinger F. Spatial Alterations between CD4+ T Follicular Helper, B, CD8+ T Cells during Simian Immunodeficiency Virus Infection: T/B Cell Homeostasis, Activation, and Potential Mechanism for Viral Escape. J Immunol. 2012; 188:32473256. [PubMed: 22387550]

68. Dandekar S, George MD, Baumler AJ. Th17 cells, HIV and the gut mucosal barrier. Curr Opin HIV AIDS. 2010; 5:173-178. [PubMed: 20543596]

69. Hunt PW. Th17, gut, HIV: therapeutic implications. Curr Opin HIV AIDS. 2010; 5:189-193. [PubMed: 20543599] 
70. Brenchley JM, Paiardini M, Knox KS, et al. Differential Th17 CD4 T-cell depletion in pathogenic and nonpathogenic lentiviral infections. Blood. 2008; 112:2826-2835. [PubMed: 18664624]

71. Favre D, Lederer S, Kanwar B, et al. Critical loss of the balance between Th17 and T regulatory cell populations in pathogenic SIV infection. PLoS Pathog. 2009; 5 e1000295.

72. Cecchinato V, Franchini G. Th17 cells in pathogenic simian immunodeficiency virus infection of macaques. Curr Opin HIV AIDS. 2010; 5:141-145. [PubMed: 20543591]

73. Ciccone EJ, Greenwald JH, Lee PI, et al. CD4+ T cells, including Th17 and cycling subsets, are intact in the gut mucosa of HIV-1-infected long-term nonprogressors. J Virol. 2011; 85:58805888. [PubMed: 21471231]

74. Demberg T, Ettinger AC, Aladi S, et al. Strong viremia control in vaccinated macaques does not prevent gradual Th17 cell loss from central memory. Vaccine. 2011; 29:6017-6028. [PubMed: 21708207]

75. Cecchinato V, Trindade CJ, Laurence A, et al. Altered balance between Th17 and Th1 cells at mucosal sites predicts AIDS progression in simian immunodeficiency virus-infected macaques. Mucosal Immunol. 2008; 1:279-288. [PubMed: 19079189]

76. Kagi D, Ledermann B, Burki K, et al. Cytotoxicity mediated by T cells and natural killer cells is greatly impaired in perforin-deficient mice. Nature. 1994; 369:31-37. [PubMed: 8164737]

77. Balkow S, Kersten A, Tran TT, et al. Concerted action of the FasL/Fas and perforin/granzyme A and B pathways is mandatory for the development of early viral hepatitis but not for recovery from viral infection. J Virol. 2001; 75:8781-8791. [PubMed: 11507223]

78. Smith-Garvin JE, Burns JC, Gohil M, et al. T-cell receptor signals direct the composition and function of the memory CD8+ T-cell pool. Blood. 116:5548-5559. [PubMed: 20847203]

79. Wiehagen KR, Corbo E, Schmidt M, Shin H, Wherry EJ, Maltzman JS. Loss of tonic T-cell receptor signals alters the generation but not the persistence of $\mathrm{CD} 8+$ memory $\mathrm{T}$ cells. Blood. 116:5560-5570. [PubMed: 20884806]

80. Rudd CE, Taylor A, Schneider H. CD28 and CTLA-4 coreceptor expression and signal transduction. Immunol Rev. 2009; 229:12-26. [PubMed: 19426212]

81. Curtsinger JM, Schmidt CS, Mondino A, et al. Inflammatory cytokines provide a third signal for activation of naive CD4+ and CD8+ T cells. J Immunol. 1999; 162:3256-3262. [PubMed: 10092777]

82. Curtsinger JM, Valenzuela JO, Agarwal P, Lins D, Mescher MF. Type I IFNs provide a third signal to CD8 T cells to stimulate clonal expansion and differentiation. J Immunol. 2005; 174:4465-4469. [PubMed: 15814665]

83. Zeng R, Spolski R, Finkelstein SE, et al. Synergy of IL-21 and IL-15 in regulating CD8+ T cell expansion and function. J Exp Med. 2005; 201:139-148. [PubMed: 15630141]

84. Parmigiani A, Pallin MF, Schmidtmayerova H, Lichtenheld MG, Pahwa S. Interleukin-21 and cellular activation concurrently induce potent cytotoxic function and promote antiviral activity in human CD8 T cells. Hum Immunol. 2011

85. Hogg AE, Bowick GC, Herzog NK, Cloyd MW, Endsley JJ. Induction of granulysin in CD8+ T cells by IL-21 and IL-15 is suppressed by human immunodeficiency virus-1. J Leukoc Biol. 2009; 86:1191-1203. [PubMed: 19687290]

86. Kaka AS, Shaffer DR, Hartmaier R, et al. Genetic modification of T cells with IL-21 enhances antigen presentation and generation of central memory tumor-specific cytotoxic T-lymphocytes. $\mathrm{J}$ Immunother. 2009; 32:726-736. [PubMed: 19561536]

87. Alves NL, Arosa FA, van Lier RA. IL-21 sustains CD28 expression on IL-15-activated human naive CD8+ T cells. J Immunol. 2005; 175:755-762. [PubMed: 16002671]

88. Chen YH, Kuo ML, Cheng PJ, Hsaio HS, Lee PT, Lin SJ. Regulation of CD28 expression on umbilical cord blood and adult peripheral blood CD8+ T cells by interleukin(IL)-15/IL-21. Cytokine. 58:40-46. [PubMed: 22261234]

89. Allard EL, Hardy MP, Leignadier J, et al. Overexpression of IL-21 promotes massive CD8+ memory T cell accumulation. Eur J Immunol. 2007; 37:3069-3077. [PubMed: 17918202]

90. Cui W, Liu Y, Weinstein JS, Craft J, Kaech SM. An interleukin-21-interleukin-10-STAT3 pathway is critical for functional maturation of memory CD8+ T cells. Immunity. 35:792-805. [PubMed: 22118527] 
91. Siegel AM, Heimall J, Freeman AF, et al. A critical role for STAT3 transcription factor signaling in the development and maintenance of human T cell memory. Immunity. 35:806-818. [PubMed: 22118528]

92. Novy P, Huang X, Leonard WJ, Yang Y. Intrinsic IL-21 signaling is critical for CD8 T cell survival and memory formation in response to vaccinia viral infection. J Immunol. 2011; 186:2729-2738. [PubMed: 21257966]

93. Hersperger AR, Pereyra F, Nason M, et al. Perforin expression directly ex vivo by HIV-specific CD8 T-cells is a correlate of HIV elite control. PLoS Pathog. 2010; 6 e1000917.

94. Migueles SA, Osborne CM, Royce C, et al. Lytic granule loading of CD8+ T cells is required for HIV-infected cell elimination associated with immune control. Immunity. 2008; 29:1009-1021. [PubMed: 19062316]

95. Schmitz JE, Kuroda MJ, Santra S, et al. Control of viremia in simian immunodeficiency virus infection by CD8+ lymphocytes. Science. 1999; 283:857-860. [PubMed: 9933172]

96. Alter G, Altfeld M. NK cells in HIV-1 infection: evidence for their role in the control of HIV-1 infection. J Intern Med. 2009; 265:29-42. [PubMed: 19093958]

97. Tiemessen CT, Shalekoff S, Meddows-Taylor S, et al. Natural killer cells that respond to human immunodeficiency virus type 1 (HIV-1) peptides are associated with control of HIV-1 infection. J Infect Dis. 2010; 202:1444-1453. [PubMed: 20874516]

98. Champagne P, Ogg GS, King AS, et al. Skewed maturation of memory HIV-specific CD8 T lymphocytes. Nature. 2001; 410:106-111. [PubMed: 11242051]

99. Mueller YM, Petrovas C, Do DH, et al. Early establishment and antigen dependence of simian immunodeficiency virus-specific CD8+ T-cell defects. J Virol. 2007; 81:10861-10868. [PubMed: 17670818]

100. White L, Krishnan S, Strbo N, et al. Differential effects of IL-21 and IL-15 on perforin expression, lysosomal degranulation, and proliferation in CD8 T cells of patients with human immunodeficiency virus-1 (HIV). Blood. 2007; 109:3873-3880. [PubMed: 17192392]

101. Iannello A, Boulassel MR, Samarani S, et al. IL-21 enhances NK cell functions and survival in healthy and HIV-infected patients with minimal stimulation of viral replication. J Leukoc Biol. 2010; 87:857-867. [PubMed: 20103765]

102. Krensky AM, Clayberger C. Biology and clinical relevance of granulysin. Tissue Antigens. 2009; 73:193-198. [PubMed: 19254247]

103. Mehta DS, Wurster AL, Whitters MJ, Young DA, Collins M, Grusby MJ. IL-21 induces the apoptosis of resting and activated primary B cells. J Immunol. 2003; 170:4111-4118. [PubMed: 12682241]

104. Recher M, Berglund LJ, Avery DT, et al. IL-21 is the primary common gamma chain-binding cytokine required for human B-cell differentiation in vivo. Blood. 2011; 118:6824-6835. [PubMed: 22039266]

105. Rankin AL, MacLeod H, Keegan S, et al. IL-21 receptor is critical for the development of memory B cell responses. J Immunol. 2011; 186:667-674. [PubMed: 21169545]

106. Avery DT, Deenick EK, Ma CS, et al. B cell-intrinsic signaling through IL-21 receptor and STAT3 is required for establishing long-lived antibody responses in humans. J Exp Med. 2010; 207:155-171. [PubMed: 20048285]

107. Kurosaki T, Shinohara H, Baba Y. B cell signaling and fate decision. Annu Rev Immunol. 2010; 28:21-55. [PubMed: 19827951]

108. Bryant VL, Ma CS, Avery DT, et al. Cytokine-mediated regulation of human B cell differentiation into Ig-secreting cells: predominant role of IL-21 produced by CXCR5+ T follicular helper cells. J Immunol. 2007; 179:8180-8190. [PubMed: 18056361]

109. Zotos D, Coquet JM, Zhang Y, et al. IL-21 regulates germinal center B cell differentiation and proliferation through a B cell-intrinsic mechanism. J Exp Med. 2010; 207:365-378. [PubMed: 20142430]

110. Diehl SA, Schmidlin H, Nagasawa M, et al. STAT3-mediated up-regulation of BLIMP1 Is coordinated with BCL6 down-regulation to control human plasma cell differentiation. J Immunol. 2008; 180:4805-4815. [PubMed: 18354204] 
111. Johnston RJ, Poholek AC, DiToro D, et al. Bcl6 and Blimp-1 are reciprocal and antagonistic regulators of $\mathrm{T}$ follicular helper cell differentiation. Science. 2009; 325:1006-1010. [PubMed: 19608860]

112. Linterman MA, Beaton L, Yu D, et al. IL-21 acts directly on B cells to regulate Bcl-6 expression and germinal center responses. J Exp Med. 2010; 207:353-363. [PubMed: 20142429]

113. Moir S, Fauci AS. B cells in HIV infection and disease. Nat Rev Immunol. 2009; 9:235-245. [PubMed: 19319142]

114. van Grevenynghe J, Cubas RA, Noto A, et al. Loss of memory B cells during chronic HIV infection is driven by Foxo3a- and TRAIL-mediated apoptosis. J Clin Invest. 2011; 121:38773888. [PubMed: 21926463]

115. Malaspina A, Moir S, Orsega SM, et al. Compromised B cell responses to influenza vaccination in HIV-infected individuals. J Infect Dis. 2005; 191:1442-1450. [PubMed: 15809902]

116. Moir S, Malaspina A, Ho J, et al. Normalization of B cell counts and subpopulations after antiretroviral therapy in chronic HIV disease. J Infect Dis. 2008; 197:572-579. [PubMed: 18240953]

117. Pallikkuth S, Rogers K, Villinger F, et al. Interleukin-21 administration to rhesus macaques chronically infected with simian immunodeficiency virus increases cytotoxic effector molecules in T cells and NK cells and enhances B cell function without increasing immune activation or viral replication. Vaccine. 2011; 29:9229-9238. [PubMed: 21996099]

118. Pallikkuth S, Pilakka Kanthikeel S, Silva SY, Fischl M, Pahwa R, Pahwa S. Upregulation of IL-21 receptor on B cells and IL-21 secretion distinguishes novel 2009 H1N1 vaccine responders from nonresponders among $\mathrm{HIV}$-infected persons on combination antiretroviral therapy. $\mathrm{J}$ Immunol. 2011; 186:6173-6181. [PubMed: 21531891]

119. Pallikkuth S, Kanthikeel SP, Silva SY, Fischl M, Pahwa R, Pahwa S. Innate immune defects correlate with failure of antibody responses to H1N1/09 vaccine in HIV-infected patients. J Allergy Clin Immunol. 2011; 128:1279-1285. [PubMed: 21752440]

120. Avery DT, Bryant VL, Ma CS, de Waal Malefyt R, Tangye SG. IL-21-induced isotype switching to $\mathrm{IgG}$ and IgA by human naive B cells is differentially regulated by IL-4. J Immunol. 2008; 181:1767-1779. [PubMed: 18641314]

121. Borte S, Pan-Hammarstrom Q, Liu C, et al. Interleukin-21 restores immunoglobulin production ex vivo in patients with common variable immunodeficiency and selective IgA deficiency. Blood. 2009; 114:4089-4098. [PubMed: 19738033]

122. Konforte D, Simard N, Paige CJ. IL-21: an executor of B cell fate. J Immunol. 2009; 182:17811787. [PubMed: 19201828]

123. Strbo N, de Armas L, Liu H, Kolber MA, Lichtenheld M, Pahwa S. IL-21 augments natural killer effector functions in chronically HIV-infected individuals. AIDS. 2008; 22:1551-1560. [PubMed: 18670213]

124. Beq S, Nugeyre MT, Ho Tsong Fang R, et al. IL-7 induces immunological improvement in SIVinfected rhesus macaques under antiviral therapy. J Immunol. 2006; 176:914-922. [PubMed: 16393976]

125. Fry TJ, Moniuszko M, Creekmore S, et al. IL-7 therapy dramatically alters peripheral T-cell homeostasis in normal and SIV-infected nonhuman primates. Blood. 2003; 101:2294-2299. [PubMed: 12411295]

126. Moniuszko M, Edghill-Smith Y, Venzon D, et al. Decreased number of CD4+ and CD8+ T cells that express the interleukin-7 receptor in blood and tissues of SIV-infected macaques. Virology. 2006; 356:188-197. [PubMed: 16934309]

127. Craiu A, Barouch DH, Zheng XX, et al. An IL-2/Ig fusion protein influences CD4+ T lymphocytes in naive and simian immunodeficiency virus-infected Rhesus monkeys. AIDS Res Hum Retroviruses. 2001; 17:873-886. [PubMed: 11461674]

128. Villinger F, Miller R, Mori K, et al. IL-15 is superior to IL-2 in the generation of long-lived antigen specific memory CD4 and CD8 T cells in rhesus macaques. Vaccine. 2004; 22:3510 3521. [PubMed: 15308379] 
129. Mueller YM, Petrovas C, Bojczuk PM, et al. Interleukin-15 increases effector memory CD8+t cells and NK Cells in simian immunodeficiency virus-infected macaques. J Virol. 2005; 79:4877-4885. [PubMed: 15795273]

130. Picker LJ, Reed-Inderbitzin EF, Hagen SI, et al. IL-15 induces CD4 effector memory T cell production and tissue emigration in nonhuman primates. J Clin Invest. 2006; 116:1514-1524. [PubMed: 16691294]

131. Mueller YM, Do DH, Altork SR, et al. IL-15 treatment during acute simian immunodeficiency virus (SIV) infection increases viral set point and accelerates disease progression despite the induction of stronger SIV-specific CD8+ T cell responses. J Immunol. 2008; 180:350-360. [PubMed: 18097036]

132. Villinger F, Bucur S, Chikkala NF, et al. In vitro and in vivo responses to interleukin 12 are maintained until the late SIV infection stage but lost during AIDS. AIDS Res Hum Retroviruses. 2000; 16:751-763. [PubMed: 10826482]

133. Watanabe N, Sypek JP, Mittler S, et al. Administration of recombinant human interleukin 12 to chronically SIVmac-infected rhesus monkeys. AIDS Res Hum Retroviruses. 1998; 14:393-399. [PubMed: 9546798]

\section{Biographies}

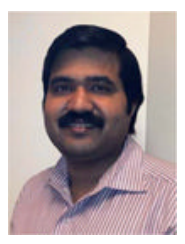

Suresh Pallikkuth, PhD is a postdoctoral research associate in the laboratory of Dr. Savita Pahwa in the Department of Microbiology and Immunology, University of Miami Miller School of Medicine. Dr. Pallikkuth received his PhD in Immunology from the PostGraduate Institute of Medical Education and Research, Chandigarh, India where he studied the host genetic and immune factors associated with protective immunity against HIV in a group of HIV exposed but uninfected individuals. His current research focus is on the immunopathogenesis of HIV infection. Currently he is working on a research project to understand how IL-21 modulates the antiviral immune response against HIV/SIV infection. This work has identified the in vivo activity of IL-21 in enhancing T, B and NK cell functions in chronically SIV infected rhesus macaques. He is also investigating the immunologic mechanisms that are involved in a successful response to Influenza vaccines in HIV infected patients and how vaccine induced immune responses are influenced by IL-21 secreting cells and plasma levels of IL-21.

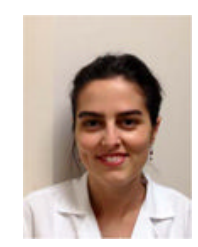

Anita Parmigiani, PhD is a postdoctoral research associate in the laboratory of Dr. Savita Pahwa at the Department of Microbiology and Immunology, University of Miami Miller School of Medicine. Dr. Parmigiani holds a Ph.D. in Immunology from the University of Milan, Italy. She has a strong interest in human immunology, with a focus on HIV immunopathogenesis. Her current research is aimed to understand the immunomodulatory role of IL-21 on T cell function. She is also interested in the HIV-associated health problems that affect HIV infected women, especially in the contest of aging. She is conducting studies to evaluate the impact of HIV infection on the immune system of post-menopausal women. 


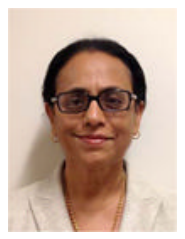

Savita Pahwa, MD is Professor of Microbiology and Immunology, Pediatrics and Medicine and Director of the Miami Center for AIDS Research (CFAR) at the University of Miami, Miller School of Medicine. Dr. Pahwa received her medical education at the Lady Harding Medical College in New Delhi, India, completed a Pediatric Residency at Kings County Hospital-Downstate Medical Center in Brooklyn, New York and specialized in Immunology and Immune Deficiency Diseases at the Memorial Hospital and Sloan Kettering Institute in New York City. Dr. Pahwa has been involved in HIV/AIDS treatment and research from the beginning of the epidemic. She has $>250$ research publications and book chapters and has served on several HIV/AIDS review panels. She is trained in clinical and laboratory immunology. Her current research interests include pathogenesis of HIV disease progression in adults and children, gut microbial translocation, aberrant immune activation, ART and immune restoration, immune responses to vaccines, $\mathrm{T}$ follicular helper cells and role of the cytokine IL-21 as a HIV vaccine adjuvant. 


\section{Table 1}

Immunomodulatory effects of cytokine administration to chronically SIV-infected Rhesus macaques.

\begin{tabular}{lcccc}
\hline & IL-21 [117] & IL-7 [124, 125] & IL-15 [129, 130] & IL-12 [132, 133] \\
\hline Perforin and granzyme B levels in CD4, CD8 and NK cells & $\uparrow$ & N.A. & N.A. & N.A. \\
\hline SIV-specific CD8 T cell polyfunctionality & $\uparrow$ & N.A. & $=$ & $\uparrow$ IFN- $\gamma$ response \\
\hline Viral set point & $=$ & $=$ & $\uparrow$ not significant & $=$ \\
\hline CD4 T cell count & $=$ & $\uparrow$ naïve & $\uparrow$ effector memory & $\downarrow$ transient \\
\hline CD8 T cell count & $=$ & $\uparrow$ transient & $\uparrow$ effector memory & $\downarrow$ transient \\
\hline CD8 T cell activation & $=$ & $\uparrow$ & $\uparrow$ & N.A. \\
\hline Frequency of memory B cells & $\uparrow$ & N.A. & N.A. & N.A. \\
\hline Anti-SIV antibody titers & $\uparrow$ & N.A. & N.A. & N.A. \\
\hline
\end{tabular}

$\uparrow:$ increased; $\downarrow$ : decreased; =: no change; N.A.: not analyzed. References for each cytokine are given in parenthesis. 
Table 2

IL-21-associated changes during the course of infection.

\begin{tabular}{lcc}
\hline & HIV+ versus HIV- & References \\
\hline Plasma levels of IL-21 & $\downarrow$ or $\uparrow$ & $23,24,26$ \\
\hline IL-21 production by CD4 T cells upon in vitro stimulation & $\downarrow$ & 23 \\
\hline IL-21 production by CD8 T cells upon in vitro stimulation & $\uparrow$ & 25 \\
\hline CD8 T cell in vitro responsiveness to IL-21 (induction of perforin, granzyme B) & $\uparrow$ & 100,22 \\
\hline IL-21-induced granulysin production by CD8 T cells & $\downarrow$ & 85 \\
\hline NK cell in vitro responsiveness to IL-21 & $\uparrow$ & 101,123 \\
\hline Upregulation of IL-21R in B cells after seasonal influenza vaccination & $\downarrow$ & 118 \\
\hline Upregulation of IL-21 plasma levels after seasonal influenza vaccination & $\downarrow$ & 118 \\
\hline
\end{tabular}

$\uparrow:$ increased; $\downarrow$ : decreased. 